\title{
Qualidade na prestação de serviços sob a perspectiva do modelo Servqual: um estudo de caso na empresa Ganache Bolos
}

\author{
Quality in service provision from the perspective of the Servqual model: a case \\ study in the company Ganache Bolos
}

Andrey Sartori ${ }^{*}$, Luis Loni ${ }^{1}$, Bárbara Perez ${ }^{1}$, Abraão Nazário ${ }^{1}$, Esdras de Jesus ${ }^{1}$, Alessandro

Oliveira $^{1}$, Moisés Botelhoํㅜ, Fabricio de Moraes ${ }^{2}$

\begin{abstract}
RESUMO
Mensurar a qualidade de um serviço prestado estando ele ligado a um produto ou não é a chave para o sucesso e destaque da mesma no mercado onde ela se estabeleceu. A qualidade de um serviço pode ser mensurada ao analisar o que o cliente vê como o ideal e o que ele percebeu após o serviço ser realizado. Partindo desse princípio, este artigo tem como objetivo avaliar a qualidade dos serviços prestados pela confeitaria Ganache Bolos, mensurando as percepções dos clientes por meio do modelo Servqual. Partindo da perspectiva de que os produtos estão cada vez mais igualados e de que a tecnologia tem se popularizado entre o setor, o preço dos produtos e serviços apresenta uma considerável concorrência no mercado onde o diferencial na hora da escolha será a qualidade do serviço entregue ao cliente. Tomando como base o estudo de caso realizado observou-se que todas as dimensões pesquisadas se mantiveram acima da expectativa dos clientes, sinalizando que a confeitaria até o presente momento não necessita de uma intervenção gerencial de urgência, porém a mesma pesquisa pode ser usada para aprimorar seus serviços e produtos.
\end{abstract}

Palavras-chave: Serviços; Qualidade; Servqual.

\begin{abstract}
Measuring the quality of a service provided, whether it is linked to a product or not, is the key to its success and prominence in the market where it has established itself. The quality of a service can be measured by analyzing what the customer sees as the ideal and what he or she perceived after the service was delivered. Based on this principle, this article aims to assess the quality of services provided by the Ganache Bolos confectionery, the perceptions of customers through the Servqual model. From the perspective that the products are increasingly equal and that technology has become popular among the sector, the price of products and services has great competition in the market where the difference when choosing will be the quality of the service delivered to the client. Based on the case study carried out, it was observed that all dimensions surveyed remained above the expectations of customers, signaling that the confectionery so far does not need an urgent management intervention, but the same research can be used to improve your services and products.
\end{abstract}

Keywords: Services; Quality; Servqual.

\footnotetext{
${ }^{1}$ Instuição de afiliação: FATEC SENAI MT

*E-mail: andrey.sartori@ senaimt.edu.br

${ }^{2}$ Instuição de afiliação diferente: IFMT
} 


\section{INTRODUÇÃO}

O setor de serviços tem crescido de forma exponencial nos últimos anos, e com isso as empresas têm buscado um diferencial para se destacar e consolidar-se no mercado regional ou até mesmo nacional.

Para tornar-se competitiva no segmento e atrativa ao cliente, essas empresas têm adotado filosofias de melhoria contínua e seguindo as tendências mercadológicas como: adaptar-se às mudanças de perfil de clientes e famílias, a maior interação com dos mesmos com a tecnologia, tamanhos e porções reduzidos dos produtos e serviços oferecidos pela empresa e sempre associado a uma excelente qualidade na prestação do serviço.

Segundo Jacques Horovitz (1993), dizia que: “só o cliente é juiz da qualidade do serviço. Portanto sua opinião é primordial" e que "é o cliente quem determina o nível de excelência de um serviço, e ele sempre quer mais". A cada serviço prestado o cliente avalia sua expectativa e percepção antes, durante e após o atendimento, aumentando assim sua expectativa na sua próxima aquisição do serviço onde terá que ser igual ou melhor que o anterior.

Importante colocação de Tom Peters (1987) "toda empresa deve provocar uma revolução de melhora na qualidade e assegurar que esta seja sempre definida em termos das percepções dos clientes" Segundo ele ainda, "esta revolução significa comer, dormir e respirar qualidade. A obsessão e a persistência da Administração em todos os níveis são essenciais. Mas a paixão deve ser equilibrada com um processo detalhado e o cliente deve estar sempre presente como principal definidor do que é importante”. De acordo com Richard Whiteley (1992), "ganharão o jogo as empresas que têm como missão não só satisfazer como exceder as expectativas de seus clientes".

Assim, uma empresa de qualidade deve se preocupar com o aspecto inovador e procurar aproveitar as oportunidades do mercado para ter uma percepção rápida de seus clientes para conseguir suprir suas necessidades. Ishikawa (1997) diz: " rápida percepção e satisfação do cliente das necessidades do mercado, adequação ao uso dos produtos e homogeneidade dos resultados dos processos".

O objetivo geral deste trabalho é realizar uma pesquisa de campo para mensurar a percepção do cliente em relação à qualidade dos serviços prestados na confeitaria 
Ganache Bolos localizada na Avenida Governador Dante Martins de Oliveira, 3305 na cidade de Cuiabá - MT. Tendo como objetivo específico identificar a insatisfação dos clientes e sugerir planos de ação nos índices que apresentarem uma percepção abaixo do padronizado pela empresa. Onde os índices que apresentarem uma melhor percepção superam a expectativa do cliente.

\section{REFERÊNCIAL TEÓRICO SERVIÇOS}

Ao longo dos anos ocorreram muitas mudanças na forma de se prestar um serviço e nas novas modalidades de serviços. Hoje são encontradas várias definições diferentes para esse termo, que vem crescendo cada vez mais no mercado.

Para se caracterizar com serviço, é importante conhecer suas características. É preciso que este esteja enquadrado dentro de cinco características básicas, são elas, a participação do cliente no processo, simultaneidade, perecibilidade, intangibilidade e heterogeneidade. VALERIE ZEITHAML (2014).

A participação do cliente se refere à presença física dele no local da prestação do serviço. Quando o cliente está presente deverá haver um maior cuidado com o ambiente e as instalações, o que não ocorre no caso das grandes fábricas, alguns desses cuidados são com o layout interior, mobília, nível de ruído no local e limpeza, tudo isso pode afetar as percepções do cliente. É importante ressaltar e entender a relevância do cliente, como parte ativa do processo através do feedback que ele proporciona às empresas durante ou após o serviço executado, a atenção às suas necessidades são os maiores desafios na prestação de um serviço.

A simultaneidade refere-se à impossibilidade de se estocar um serviço, onde o mesmo é consumido à medida que é executado. Diferente da indústria manufatureira tradicional, onde se confia nos estoques para absorver as flutuações de demanda do mercado. Na prestação de serviços muitas possibilidades de controle da qualidade são eliminadas. Um produto pode ser inspecionado antes da sua entrega ao cliente, já os serviços não podem ser inspecionados antes da sua entrega podendo sofrer algum tipo de alteração por parte do prestador ou por parte do cliente contratante. Em relação aos serviços "é preciso confiar em indicadores diferentes dos que são estabelecidos para avaliar os produtos"' James Fitzsimmons (2014). 
Os serviços não podem ser armazenados, estocados, revendidos ou devolvidos. A perecibilidade é diferente dos produtos físicos, pois podem ser devolvidos e voltar ao estoque, assim em uma futura venda ser entregue a outro cliente. Por não ser estocado o serviço estará perdido caso não seja utilizado. A venda de um serviço e sua duração é um desafio gerencial, pois conforme as demandas sofrem variações e não há estocagem.

\section{QUALIDADE EM SERVIÇOS}

O conceito de qualidade evolui para a garantia de qualidade, que consiste na sistematização, por normas escritas, padrões e requisitos para cada etapa do processo produtivo. Com objetivo de garantir qualidade uniforme para todos os produtos e serviços. Tais normas são organizadas nos manuais de qualidade das empresas e são solicitadas com frequência nas relações comerciais entre clientes e fornecedores.

Na década de 60, os mercados nos países mais desenvolvidos já se encontram saturados de produtos e os consumidores vão à busca de produtos diferenciados. A alta tecnologia passa a ser adotada como ferramenta primordial nas produções visando à qualidade, padronização e evitando desperdício. As barreiras comerciais entre os países diminuem e a competição entre as empresas se intensifica. Em consequência, assumem a liderança de mercado, empresas com produtos diferenciados e preços competitivos. A qualidade volta-se, assim, para a plena satisfação do cliente. Ter um bom produto ou um produto perfeito, já não dá vantagem alguma para a empresa. A ênfase direcionada ao produto está superada. O consumidor é agora, o marco de referência para atestar a real qualidade do produto ou serviço prestado.

Jaques Harovitz (1993) já confirma que: "só o cliente é juiz da qualidade do serviço. Portanto sua opinião é primordial". Falar de "Qualidade" é modismo hoje no Brasil. Porém sua aplicabilidade requer conhecimento, esforço e uma dedicação implacável.

Valerie Zeithaml (2014) diz em seu livro Marketing de serviços que muito se fala sobre o que os consumidores levam em consideração na hora de avaliar a qualidade de um serviço. Muitos pesquisadores da área de serviços sugerem que os consumidores julgam a qualidade do serviço com base nas suas percepções do resultado técnico 
gerado, do processo pelo qual o resultado foi produzido e da qualidade do ambiente físico em que o serviço é executado.

Segundo Lacerda (2005), o que determina se um serviço é bom, são as atitudes dos clientes diante do serviço. Com isso, são levados em consideração os comportamentos, atitudes pessoais e atividades da empresa ao longo do tempo e não apenas no momento da prestação do serviço. Assim sendo, atender às necessidades dos clientes é função básica da organização para atuar no mercado e encarar a competitividade. O diferencial é surpreender o cliente de forma positiva na sua experiência e para isso acontecer é importante a participação consciente e motivada do colaborador e a sintonia com suas necessidades.

Segundo Kotler e Keller (2006), a qualidade é o conjunto dos atributos de um serviço e corresponde às necessidades explícitas ou implícitas dos clientes. A organização que satisfaz a maior parte das necessidades de seus clientes durante grande parte do tempo é apontada como uma empresa de qualidade.

Conhecer o que os clientes desejam é essencial para adequar as ações das empresas para que elas tenham qualidade em seus serviços. A organização que não busca pesquisar sobre expectativas, percepções e satisfação do cliente para compreender e mensurar o desempenho dos serviços que presta, pode ter mais dificuldades para compreender seus clientes. Já as que o fazem, podem conhecer o que precisa ser desenvolvido para adaptarem-se às mudanças das necessidades de seus clientes, segundo ZEITHAML; BITNER, 2003.

Para avaliação da percepção da qualidade de serviço dos usuários, existem vários modelos desenvolvidos ou aprimorados para cooperar nessa mensuração. $\mathrm{O}$ modelo que foi aplicado nesse estudo de caso é o modelo SERVQUAL, que se destaca por sua versatilidade, capacidade de mensurar e detalhamento da percepção do cliente.

\section{SERVQUAL}

A ferramenta SERVQUAL, surgiu do trabalho pioneiro que foi desenvolvido por Parasuraman, Zeithaml e Berry, que criou uma escala de múltiplos itens para mensurar as percepções dos consumidores sobre a qualidade dos serviços, a escala conta com 25 atributos de serviços, agrupada em cinco dimensões da qualidade dos 
serviços, que são a confiabilidade, empatia, tangibilidade, presteza e a segurança. (PARASURAMAN, A.; ZEITHAML, V. A.; BERRY, L, 1988)

Nas dimensões, a confiabilidade é a capacidade de executar o que foi prometido de forma confiável e precisa. A empatia é a atenção individual que foi dada ao cliente. A tangibilidade trata sobre a aparência das instalações físicas, dos equipamentos, funcionários e dos materiais de comunicação.

O modelo SERVQUAL é formado por 25 itens, porém para essa pesquisa foram adaptados 23 itens com o objetivo de mensurar a expectativa do cliente, onde esses mesmos itens são adaptados com o objetivo de mensurar a percepção do cliente sobre o serviço prestado por uma empresa. Estes itens refletem as cinco dimensões ou determinantes da qualidade de serviço: confiabilidade, receptividade, segurança, aspectos tangíveis e empatia (FREITAS; BOLSANELLO; CARNEIRO, 2008).

A avaliação da qualidade fundamentada no SERVQUAL leva em consideração as lacunas (gaps), que são a diferença entre as percepções dos consumidores em relação ao que foi oferecido e a expectativa que tinham do serviço, são elas:

- GAP 1 - Compreensão do cliente: é a diferença entre a expectativa do cliente e o que a empresa entende como a expectativa do cliente;

- GAP 2 - Projeto e padrões de serviço: é a diferença entre as expectativas dos clientes e as especificações da qualidade dos serviços realizados.

- GAP 3 - Desempenho do serviço: é a diferença entre a execução do serviço e os padrões definidos pelo cliente.

- GAP 4 - Comunicação: é a diferença entre a execução do serviço e a comunicação externa com o cliente.

- GAP 5 - Diferença entre a expectativa e a percepção: é a diferença entre o serviço que foi executado e o que o cliente esperava.

A dimensão Tangibilidade compara as expectativas do cliente com o desempenho da empresa referente à sua capacidade de administrar seus tangíveis, isto é, a variedade de 25 objetos envolvidos na prestação do serviço: instalações, equipamentos, folhetos, correspondência, cartões de visita e a aparência dos profissionais envolvidos. É obtida por meio de quatro perguntas sobre Expectativas e quatro sobre Percepções, conforme mostrado no Quadro 1: 
Quadro 1 - Itens de expectativas e percepções na dimensão "Tangibilidade”:

\begin{tabular}{|l|l|l|}
\hline Item & Expectativa & Percepção \\
\hline $\mathbf{1}$ & Ela deveria ter equipamentos modernos & XYZ tem equipamentos modernos. \\
\hline $\mathbf{2}$ & $\begin{array}{l}\text { As suas instalações físicas deveriam ser } \\
\text { atrativas. }\end{array}$ & $\begin{array}{l}\text { As instalações físicas de XYZ são } \\
\text { atrativas. }\end{array}$ \\
\hline $\mathbf{3}$ & $\begin{array}{l}\text { Os seus empregados deveriam estar bem } \\
\text { vestidos e asseados. }\end{array}$ & $\begin{array}{l}\text { Os empregados de XYZ são bem } \\
\text { vestidos e asseados. }\end{array}$ \\
\hline $\mathbf{4}$ & $\begin{array}{l}\text { A aparência das instalações da empresa } \\
\text { deveria estar bem conservada de acordo } \\
\text { com o serviço oferecido. }\end{array}$ & $\begin{array}{l}\text { A aparência das instalações da XYZ } \\
\text { é bem conservada de acordo com o } \\
\text { serviço oferecido. }\end{array}$ \\
\hline
\end{tabular}

Fonte: Hoffman e Bateson (2006) e Parasuraman, Zeithaml e Berry (1994)

A dimensão Confiabilidade reflete a coerência e a confiança que o desempenho de uma empresa inspira. Refere-se essa dimensão à confiança nos serviços profissionais da empresa e na sua capacidade de cumprir o que combinou com o cliente. Obtida por meio de cinco perguntas sobre Expectativas e cinco sobre Percepções, conforme mostrado no Quadro 2:

Quadro 2 - Itens de expectativas e percepções na dimensão Confiabilidade, conforme mostrado no quadro 2 abaixo:

\begin{tabular}{|c|c|c|}
\hline Item & Expectativa & Percepção \\
\hline 5 & $\begin{array}{l}\text { Quando estas empresas prometem fazer } \\
\text { algo em certo tempo deveriam fazê-lo. }\end{array}$ & $\begin{array}{l}\text { Quando XYZ promete fazer algo em } \\
\text { certo tempo, ela o faz. }\end{array}$ \\
\hline 6 & $\begin{array}{l}\text { Quando os clientes tem algum problema } \\
\text { com esta empresa, ela deveria ser } \\
\text { solidária e deixá-los seguros. }\end{array}$ & $\begin{array}{l}\text { Quando os clientes tem algum } \\
\text { problema com a empresa XYZ, ela é } \\
\text { solidária e o deixa seguro. }\end{array}$ \\
\hline 7 & Esta empresa deveria ser de confiança. & XYZ é de confiança. \\
\hline 8 & $\begin{array}{l}\text { Ela deveria fornecer o serviço no tempo } \\
\text { prometido. }\end{array}$ & $\begin{array}{l}\text { XYZ fornece o serviço no tempo } \\
\text { prometido. }\end{array}$ \\
\hline 9 & $\begin{array}{l}\text { Ela deveria manter seus registros de } \\
\text { forma correta. }\end{array}$ & $\begin{array}{l}\text { XYZ mantém seus registros de } \\
\text { forma correta. }\end{array}$ \\
\hline
\end{tabular}

Fonte: Hoffman e Bateson (2006) e Parasuraman, Zeithaml e Berry (1994)

A dimensão Receptividade (responsabilidade, ou sensibilidade) se refere à disposição em servir os clientes, oferecendo de imediato os serviços ao cliente, o fato de deixá-lo esperando o primeiro contato, forma uma percepção negativa da qualidade 
dos serviços. A pesquisa é obtida por meio de quatro perguntas sobre Expectativas e quatro sobre Percepções, conforme mostrado quadro 3:

Quadro 3 - Itens de expectativas e percepções na dimensão "Receptividade":

\begin{tabular}{|l|l|l|}
\hline Item & Expectativa & Percepção \\
\hline $\mathbf{1 0}$ & $\begin{array}{l}\text { Não seria de se esperar que ela } \\
\text { informasse os clientes quando os } \\
\text { serviços fossem executados. }\end{array}$ & $\begin{array}{l}\text { XYZ não informa com precisão } \\
\text { quando os serviços serão executados. }\end{array}$ \\
\hline $\mathbf{1 1}$ & $\begin{array}{l}\text { Não é razoável esperar por uma } \\
\text { disponibilidade imediata dos } \\
\text { empregados da empresa. }\end{array}$ & $\begin{array}{l}\text { Você recebe o serviço imediato dos } \\
\text { empregados da XYZ. }\end{array}$ \\
\hline $\mathbf{1 2}$ & $\begin{array}{l}\text { Os empregados das empresas não estão } \\
\text { sempre disponíveis para ajudar os } \\
\text { clientes. }\end{array}$ & $\begin{array}{l}\text { Os empregados da XYZ não estão } \\
\text { sempre dispostos a ajudar os clientes. }\end{array}$ \\
\hline $\mathbf{1 3}$ & $\begin{array}{l}\text { É normal que eles estejam muito } \\
\text { ocupados em responder aos pedidos no } \\
\text { momento da solicitação. }\end{array}$ & $\begin{array}{l}\text { Empregados da XYZ estão sempre } \\
\text { ocupados em responder aos pedidos } \\
\text { dos clientes. }\end{array}$ \\
\hline
\end{tabular}

Adaptado de Hoffman e Bateson (2006) e Parasuraman, Zeithaml e Berry (1994)

A dimensão Segurança diz respeito à competência da empresa em relação a realização dos serviços que são oferecidos ao cliente, à cortesia que ela oferece e à segurança de suas operações. A competência refere-se ao conhecimento técnico e às habilidades que a empresa possui para realizar os serviços de maneira profissional e segura. A pesquisa é realizada por meio de quatro perguntas sobre Expectativas e quatro sobre Percepções, conforme mostrado no Quadro 4.

Quadro 4 - Itens de expectativas e percepções da dimensão "Segurança":

\begin{tabular}{|l|l|l|}
\hline Item & Expectativa & Percepção \\
\hline $\mathbf{1 4}$ & $\begin{array}{l}\text { Clientes deveriam ser capazes de } \\
\text { acreditar nos empregados desta } \\
\text { empresa. }\end{array}$ & $\begin{array}{l}\text { Você pode acreditar nos empregados } \\
\text { da XYZ. }\end{array}$ \\
\hline $\mathbf{1 5}$ & $\begin{array}{l}\text { Clientes deveriam ser capazes de se } \\
\text { sentir seguros na negociação com os } \\
\text { empregados da empresa. }\end{array}$ & $\begin{array}{l}\text { Você se sente seguro em negociar } \\
\text { com os empregados da XYZ. }\end{array}$ \\
\hline $\mathbf{1 6}$ & $\begin{array}{l}\text { Seus empregados deveriam ser } \\
\text { educados. }\end{array}$ & Empregados da XYZ são educados. \\
\hline
\end{tabular}




\begin{tabular}{|l|l|l|}
\hline 17 & $\begin{array}{l}\text { Seus empregados deveriam obter } \\
\text { suporte adequado da empresa para } \\
\text { cumprir suas tarefas de forma correta. }\end{array}$ & $\begin{array}{l}\text { Os empregados da XYZ não obtêm } \\
\text { suporte adequado da empresa para } \\
\text { cumprir suas tarefas de forma correta. }\end{array}$ \\
\hline
\end{tabular}

Adaptado de Hoffman e Bateson (2006) e Parasuraman, Zeithaml e Berry (1994)

A dimensão Empatia refere-se à demonstração de interesse por parte da empresa e fornecer atenção individualizada aos clientes. A pesquisa é realizada por meio de quatro perguntas sobre Expectativas e quatro sobre Percepções, conforme mostrado no Quadro 5.

Quadro 5 - Itens de expectativas e percepções da dimensão "Empatia":

\begin{tabular}{|l|l|l|l|}
\hline $\begin{array}{l}\text { Ite } \\
\mathbf{m}\end{array}$ & Expectativa & Percepção \\
\hline $\mathbf{1 8}$ & $\begin{array}{l}\text { Não seria de se esperar que a empresa } \\
\text { desse atenção individual aos clientes. }\end{array}$ & $\begin{array}{l}\text { XYZ não dá atenção individual a } \\
\text { você. }\end{array}$ \\
\hline $\mathbf{1 9}$ & $\begin{array}{l}\text { Não se pode esperar que os empregados } \\
\text { deem atenção personalizada aos clientes. }\end{array}$ & $\begin{array}{l}\text { Os empregados da XYZ não dão } \\
\text { atenção pessoal. }\end{array}$ \\
\hline $\mathbf{2 0}$ & $\begin{array}{l}\text { É absurdo esperar que os empregados } \\
\text { saibam quais são as necessidades dos } \\
\text { clientes. }\end{array}$ & $\begin{array}{l}\text { Os empregados da XYZ não sabem } \\
\text { das suas necessidades. }\end{array}$ \\
\hline $\mathbf{2 1}$ & $\begin{array}{l}\text { É absurdo esperar que esta empresa } \\
\text { tenha os melhores interesses de seus } \\
\text { clientes como objetivo. }\end{array}$ & $\begin{array}{l}\text { XYZ não tem seus melhores } \\
\text { interesses como objetivo. }\end{array}$ \\
\hline $\mathbf{2 2}$ & $\begin{array}{l}\text { Não deveria se esperar que o horário de } \\
\text { funcionamento fosse conveniente para } \\
\text { todos os clientes. }\end{array}$ & $\begin{array}{l}\text { XYZ não tem os horários de } \\
\text { funcionamento convenientes a todos } \\
\text { os clientes. }\end{array}$ \\
\hline
\end{tabular}

Adaptado de Hoffman e Bateson (2006) e Parasuraman, Zeithaml e Berry (1994)

Segundo Loures (2009), diz que o modelo SERVQUAL é um "esqueleto" básico por meio do seu formato de expectativas e percepções que engloba sentenças para cada uma das cinco dimensões da qualidade de serviço. Esse "esqueleto" pode ser adaptado a qualquer pesquisa de mensuração de serviços, quando necessário e complementado para atender as necessidades de cada pesquisa e cada empresa.

Segundo Fitzsimmons e Fitzsimmons (2000) medir a qualidade do serviço prestado é um desafio para a empresa, pois está ligada de forma direta com a satisfação 
do cliente e, essa é constituída por vários fatores intangíveis (que não pode ser medida de forma fácil). Essa ferramenta pode ser utilizada para:

a) para medir a qualidade dos serviços, e pode ser utilizada de forma conjunta com outras formas de medida de qualidade do serviço, como por exemplo, reclamações e sugestões de clientes;

b) para categorizar os clientes de uma organização em segmentos diferentes associados à percepção de qualidade que os mesmos têm da empresa e sugerir estratégias diferenciadas;

c) para acessar o desempenho dos seus principais concorrentes em cada uma das dimensões;

d) para ter uma avaliação geral da qualidade dos serviços;

e) para determinar a importância relativa das dimensões na avaliação geral da percepção de qualidade dos serviços feita pelos clientes em relação a uma organização, apresentando quais são as mais críticas e as que merecem atenção especial.

A avaliação da qualidade é realizada subtraindo o desempenho percebido pelas expectativas mensuradas na avaliação. Após esta etapa serão calculadas as pontuações obtidas nas percepções e nas expectativas. Caso a percepção seja maior que a expectativa a empresa está trabalhando de maneira adequada, caso contrário ocorre a presença do gap. O resultado obtido através da pesquisa ajudará a empresa a definir a satisfação do cliente e o que influencia na percepção do cliente sobre o serviço que está sendo prestado (SOUZA, 2008).

\section{METODOLOGIA}

Esta seção apresenta a metodologia que foi usada para o desenvolvimento do trabalho, destacando o tipo de pesquisa e a forma como os dados foram coletados, analisados e interpretados. "A metodologia descreve como o projeto será realizado" Roesch (2005, p.125). E segundo Corrobora Richardson (1999), afirma que "a metodologia constitui a conjuntura dos caminhos a serem seguidos, dos instrumentos usados para se fazer ciência, ou ainda, o modo como se conduz uma pesquisa, a caracterização, sujeito de pesquisa, os instrumentos, bem como, análise e coleta de dados". 
Foi adotado nesta pesquisa somente a percepção dos clientes, uma vez que os mesmos não tinham como avaliar a expectativa, pois já eram clientes da empresa. Sendo assim foi padronizado pela empresa uma nota 4 (Ótima) para todas as perguntas, sendo feita a comparação somente com a resposta da percepção.

\section{TIPO DA PESQUISA E AMOSTRA}

Quanto a sua natureza, a pesquisa é do tipo aplicada, pois, tem como objetivo gerar conhecimento para aplicação prática e dirigido a solução de problemas. Quanto ao ponto de vista da forma de abordagem ela é qualitativa e quantitativa, uma vez que as opiniões dos clientes são quantificadas e é feita uma análise com base nos dados coletados para identificar as possíveis causas dos problemas na confeitaria.

Exploratória em relação aos seus objetivos, pois envolve a aplicação de entrevistas com o cliente e Survey em seus procedimentos técnicos, pois visa determinar as percepções dos clientes em relação ao serviço prestado pela confeitaria comparando com uma expectativa padrão. A abordagem definida neste trabalho é considerada nãoprobabilística com amostragem por conveniência, ou seja, a seleção de avaliadores foi definida a partir da facilidade de acesso aos elementos por parte do pesquisador (MALHOTRA, 2006).

\section{INSTRUMENTO DA PESQUISA}

O instrumento de coleta de dados utilizado na pesquisa foi o questionário formulado no Googleforms, adaptado do modelo SERVQUAL de Parasuraman, Zeithaml e Berry (1985), e disponibilizado via link aos respondentes, tendo em vista o ramo da empresa em análise, conforme mostrado nas etapas acima. O modelo SERVQUAL foi escolhido devido ao mesmo exibir as características necessárias para a coleta de dados e por ter sido exposto em muitos artigos científicos como instrumento adequado para medir a qualidade de serviços prestados.

O questionário é constituído por 23 questões objetivas que abordam a Dimensão Percepção da Qualidade dos Serviços da Confeitaria Ganache Bolos. 


\section{ESCALA LIKERT}

A escala Likert (Figura 1) é um modelo de escala de questionários usado em pesquisas de opinião e de satisfação de clientes, onde a mesma permite mensurar o ponto de vista e a postura dos consumidores de forma escalonada, indo, por exemplo, de "péssimo" a "excelente".

Criada por Rensis Likert, professor de sociologia, psicologia e diretor do Instituto de Pesquisas Sociais de Michigan, a proposta da escala Likert é verificar quanto os clientes concordam ou não com uma afirmação, por exemplo, "A nossa solução foi fácil de ser instalada?"

É através desse retorno do cliente, obtido pela escala Likert mensurando e obtendo dados que serão aprimoradas nossas ofertas, o atendimento ao cliente, e diversos outros pontos da sua empresa, tendo como base a percepção de quem compra da sua marca. Para esse trabalho foi utilizado uma escala de 1 a 5 pontos de forma quantitativa e qualitativa (péssima, ruim, boa, ótima e excelente).

Figura 1 - Escala Likert

\begin{tabular}{|c|c|c|c|c|}
\hline 5 & 4 & 3 & 2 & 1 \\
\hline Excelente & Ótimo & Bom & Ruim & Péssimo \\
\hline
\end{tabular}

Fonte: adaptado pelos autores, 2021

A equação que medirá a qualidade do serviço será $\left(\mathbf{Q}=\sum \overline{\mathbf{X}} \mathbf{P}-\sum \overline{\mathbf{X}} \mathbf{E}\right)$, sendo “Q” o padrão de qualidade estabelecida pela a somatória da média da Percepção " $\sum \overline{\mathbf{X}} \mathbf{P}$ " menos a somatória da média da Expectativa " $\sum \overline{\mathbf{X}} \mathbf{E}$ ". A diferença $(\mathbf{Q})$ tendo o valor menor que 4,0 (Ótimo) indicam que os usuários têm a percepção abaixo das expectativas estando o serviço abaixo do nível aceitável e suas expectativas não foi atendida. No oposto, o item (Q) maior que 4,0 (Ótimo) ultrapassa as expectativas esperadas pelo usuário e em um cenário onde $(\mathbf{P}=\mathbf{E})$ o serviço foi oferecido de forma satisfatória ao usuário. Conforme Suarez (2015), se o serviço estiver entre $40 \%$ e $80 \%$ encontra-se na zona de indiferença do cliente e acima de $80 \%$ chega à zona de fidelização uma vez que o serviço está sendo oferecido de maneira satisfatória. Por 
outro lado, avaliação abaixo de $40 \%$ entra na zona de defecção onde o cliente não tem suas necessidades satisfeitas (Figura 2).

Figura 2: Percentuais de satisfação dos usuários

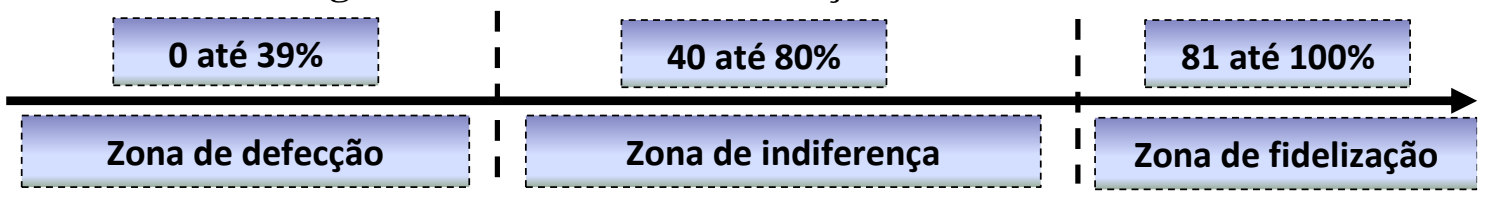

Fonte: Adaptado de Suarez, 2015

Portanto para chegar ao índice de satisfação divide-se a média geral de cada dimensão pela nota máxima da escala de Likert para se obter o percentual da taxa de satisfação, expressado pelo equação $\left(\sum \overline{\mathrm{X}} / 5\right)$.

\section{ANÁLISE DOS DADOS}

Segundo Mattar (1999), “[dados primários são aqueles que não foram antes coletados, estando ainda em posse dos pesquisados, e que são coletados com o propósito de atender às necessidades específicas da pesquisa em andamento", e dados secundários "são aqueles que já foram coletados, tabulados, ordenados e, às vezes, até analisados, com propósitos outros ao de atender às necessidades da pesquisa em andamento, e que são catalogados à disposição dos interessados”.

Sendo assim, os dados primários foram coletados através de questionários com questões objetivas que foram aplicados aos clientes da empresa. Após a coleta dos dados, os mesmos foram tabulados e analisados para verificar a percepção e expectativa dos clientes quanto aos serviços da confeitaria. O objetivo foi descobrir qual era a pontuação geral de cada uma das questões do formulário. A análise dos dados foi feita através de análise descritiva e após isso convertida em quantitativa por meio de gráficos, planilha e porcentagem. A seguir são apresentadas a análise e interpretação dos resultados da pesquisa. 


\section{RESULTADOS E DISCUSSÕES}

Essa seção apresenta os resultados que foram obtidos do dia 25\05\2021 ao dia 2310612021 coletando 172 pesquisas respondidas, após a análise dos dados colhidos, através dos questionários.

\section{CARACTERIZAÇÃO DA EMPRESA}

A pesquisa foi aplicada em uma confeitaria fundada em outubro de 2015. Uma empresa familiar que nasceu de uma paixão por bolos e produtos de confeitaria. Localizada na região da cidade de Cuiabá, no estado de Mato Grosso. A mesma está em funcionamento há seis anos no mesmo local, vendendo produtos de produção própria, com opções de personalização da montagem do produto pelo cliente.

O quadro de funcionários é composto por uma chefa de confeitaria, uma auxiliar de produção, um atendente e um Motoboy. O horário de funcionamento é de segunda a sexta feira das 9:00 horas ás 12:00 horas e das 13:30 horas ás 18:00 horas. O espaço físico é composto por uma cozinha de produção, uma cozinha de finalização de pedidos, sala de estoque e salão com balcão expositor de bolos a pronta entrega. Tendo o delivery como principal meio de entrega dos produtos.

\section{PERFIL DOS RESPONDENTES}

Em relação ao sexo dos clientes constatou-se que a maioria dos respondentes é do sexo feminino, o que representa $94 \%$ dos clientes e os $6 \%$ restantes masculinos. No que diz respeito à idade dos clientes, 1,4\% tem de 16 a 20 anos, 20,8\% têm de 21 a 25 anos, 31,9\% tem de 26 a 30 anos, 22,2\% têm de 31 a 35 anos, 9,7\% tem de 36 a 40 anos, $11,1 \%$ têm de 41 a 50 anos, 2,8\% têm de 51 a 60 anos e não houve respondentes acima de 60 anos. No que se refere ao grau de escolaridade dos entrevistados.

Nenhum dos entrevistados possui o nível fundamental, 1,4\% possuem o nível médio incompleto, 23,6\% possuem o nível médio completo, 20,8\% possuem o nível superior incompleto e que 54,2\% possuem o nível superior completo. Referente à faixa 
salarial dos pesquisados têm-se: de 51,4\% recebem entre $\mathrm{R} \$ 1.000,00$ a $\mathrm{R} \$ 2.000,00$; $20,8 \%$ recebem entre $\mathrm{R} \$ 2.001,00$ a $\mathrm{R} \$ 3.000,00 ; 12,5 \%$ recebem entre $\mathrm{R} \$ 3.001,00$ a $4.000,00 ; 1,4 \%$ recebem entre $\mathrm{R} \$ 4.001,00$ a $\mathrm{R} \$ 5.000$ e $13,9 \%$ recebem acima de $\mathrm{R} \$$ $5.001,00$. Em relação à média de compra de cada cliente foi pesquisada e obtiveram-se os seguintes resultados: 4,2\% consomem entre $\mathrm{R} \$ 15,00$ a $\mathrm{R} \$ 25,00,31,9 \%$ consomem entre $\mathrm{R} \$ 26,00$ a $\mathrm{R} \$ 35,00 ; 43,1 \%$ consomem entre $\mathrm{R} \$ 36,00$ a $\mathrm{R} \$ 45,00$ e $20,8 \%$ consomem acima de $\mathrm{R} \$ 50,00$.

\section{ANÁLISE DAS DIMENSÕES}

O SERVQUAL é uma ferramenta que ajuda na avaliação da qualidade de um serviço ao comparar a percepção do cliente em relação à execução do serviço como a expectativa. Neste artigo, a expectativa foi padronizada com nota 4 , uma vez que essa Dimensão não foi aplicada aos clientes, tendo em vista que fica inviável aplicar a mesma pelo fato da Expectativa medir a experiência do cliente que ainda não conhece os serviços do local pesquisado. O pesquisador optou junto com a empresa selecionada para elaborar o trabalho uma nota para Dimensão Expectativa quantitativa mínima de 4,0 considerada de forma qualitativa como "Ótima" dentro da escala Likert usada na pesquisa para considerar o cálculo da Percepção do cliente $\left(\mathbf{Q}=\sum \overline{\mathbf{X}} \mathbf{P}-\sum \overline{\mathbf{X}} \mathbf{E}\right)$. Sendo assim, o resultado da nota que apresentar-se abaixo da nota 4,0 (Ótima) será indicado um Plano de Ação para a confeitaria Ganache Bolos. A Tabela 1 abaixo apresenta uma análise geral dos dados obtidos com a pesquisa. 
Tabela 1 - SERVQUAL com os resultados das dimensões.

\begin{tabular}{|c|c|c|c|c|c|}
\hline DIMENSÃO & QUESTÃO & PERCEPÇÃO & EXPECTATIVA & P-E & PORCENTAGEM INDIVIDUAL \\
\hline \multirow{6}{*}{$\left\langle\nabla^{0}\right.$} & 1 & 4,68 & 4 & 0,68 & $94 \%$ \\
\hline & 2 & 4,56 & 4 & 0,56 & $91 \%$ \\
\hline & 3 & 3,88 & 4 & $-0,13$ & $78 \%$ \\
\hline & 4 & 4,1 & 4 & 0,10 & $82 \%$ \\
\hline & 5 & 4,38 & 4 & 0,38 & $88 \%$ \\
\hline & MÉDIA & 4,32 & 4 & $86 \%$ & \\
\hline \multirow{6}{*}{$c$} & 6 & 4,75 & 4 & 0,75 & $95 \%$ \\
\hline & 7 & 4,76 & 4 & 0,76 & $95 \%$ \\
\hline & 8 & 4,61 & 4 & 0,61 & $92 \%$ \\
\hline & 9 & 4,61 & 4 & 0,61 & $92 \%$ \\
\hline & 10 & 4,75 & 4 & 0,75 & $95 \%$ \\
\hline & MÉDIA & 4,70 & 4 & $\mathbf{9 4 \%}$ & \\
\hline \multirow{6}{*}{$p^{\beta^{c}}$} & 11 & 4,69 & 4 & 0,69 & $94 \%$ \\
\hline & 12 & 4,67 & 4 & 0,67 & $93 \%$ \\
\hline & 13 & 4,6 & 4 & 0,60 & $92 \%$ \\
\hline & 14 & 4,69 & 4 & 0,69 & $94 \%$ \\
\hline & 15 & 4,74 & 4 & 0,74 & $95 \%$ \\
\hline & MÉDIA & 4,68 & 4 & $94 \%$ & \\
\hline \multirow{5}{*}{$s^{\sigma^{0}}$} & 16 & 4,71 & 4 & 0,71 & $94 \%$ \\
\hline & 17 & 4,68 & 4 & 0,68 & $94 \%$ \\
\hline & 18 & 4,64 & 4 & 0,64 & $93 \%$ \\
\hline & 19 & 4,50 & 4 & 0,50 & $90 \%$ \\
\hline & MÉDIA & 4,63 & 4 & $93 \%$ & \\
\hline \multirow{5}{*}{$s^{p^{N}}$} & 20 & 4,58 & 4 & 0,58 & $92 \%$ \\
\hline & 21 & 4,65 & 4 & 0,65 & $93 \%$ \\
\hline & 22 & 4,53 & 4 & 0,53 & $91 \%$ \\
\hline & 23 & 4,68 & 4 & 0,68 & $94 \%$ \\
\hline & MÉDIA & 4,64 & 4 & $93 \%$ & \\
\hline
\end{tabular}

Fonte: Autores, 2021

Com base na Tabela 1 verificou-se que nenhuma das dimensões ficou abaixo das expectativas da confeitaria. Com isso, pode-se inferir que os clientes possuem uma ótima percepção em relação aos serviços e produtos fornecidos e prestados. Abaixo serão apresentadas as médias de cada dimensão, percepção dos clientes, médias gerais e individuais.

\section{ANÁLISE E RESULTADOS DAS DIMENSÕES}

A pesquisa foi aplicada entre os clientes da confeitaria Ganache Bolos e teve o objetivo de analisar a qualidade de serviços e produtos oferecidos por meio da escala SERVQUAL adaptada à confeitaria. Para se calcular o GAP entre a expectativa e a percepção dos clientes em relação aos aspectos questionados, foi feita a subtração da 
perspectiva menos a expectativa (P-E). Com base na média mínima padronizada e nos gaps foram feitas tabelas que facilitam a visualização da relação entre as variáveis estudadas. De tal forma foi possível identificar em quais pontos a percepção dos clientes está acima ou abaixo das suas expectativas mínimas fixadas pela confeitaria.

A Tabela 2 abaixo exibe os dados obtidos sobre a dimensão "tangibilidade" que se referem à aparência dos equipamentos, instalações físicas, pessoal e materiais de comunicação (PARASURAMAN; ZEITHAML; BERRY, 1988).

Tabela 2 - Resultados da dimensão "Tangibilidade".

\begin{tabular}{|c|c|c|c|c|c|}
\hline DIMENSÃO & QUESTÃO & PERCEPÇÃO & EXPECTATIVA & P-E & PORCENTAGEM INDIVIDUAL \\
\hline & 1 & 4,68 & 4 & 0,68 & $94 \%$ \\
\hline $0^{4}$ & 2 & 4,56 & 4 & 0,56 & $91 \%$ \\
\hline$p$ & 3 & 3,88 & 4 & $-0,13$ & $78 \%$ \\
\hline & 4 & 4,1 & 4 & 0,1 & $82 \%$ \\
\hline$\langle P$ & 5 & 4,38 & 4 & 0,38 & $88 \%$ \\
\hline & MÉDIA & 4,32 & 4 & $86 \%$ & $<=$ TAXA DE SATISFAÇÃO \\
\hline
\end{tabular}

Fonte: Autor, 2021

Observa-se na Tabela 2 que os quatro itens ficaram acima da média padronizada como o mínimo aceitável, onde apenas um item (Questão 3) ficou com apenas 3,88 uma ligeira variação de $(-0,13)$, mostrando a insatisfação dos clientes em relação ao estacionamento da confeitaria. Em relação à questão 1 (limpeza do local) tem-se 94\% de satisfação, questão 2 (estruturalOrganização) obteve-se 91\% de satisfação. Questão 4 (Visibilidade e fachada) obteve-se 82\% de satisfação e questão 5 (Localização) obtevese $88 \%$ de satisfação dos clientes. Ao final dos dados analisados pela planilha SERVQUAL, obteve-se uma satisfação geral da dimensão “Tangibilidade” de $86 \%$ dos clientes.

Sugeriu-se a confeitaria Ganache Bolos uma análise mais minuciosa em relação à questão 3 (Estacionamento), reforma, sinalização ou ampliação do espaço. Abaixo o histograma da dimensão tangibilidade ilustrando os dados no diagrama de Pareto. 
Gráfico 1 - Histograma dimensão "Tangibilidade"

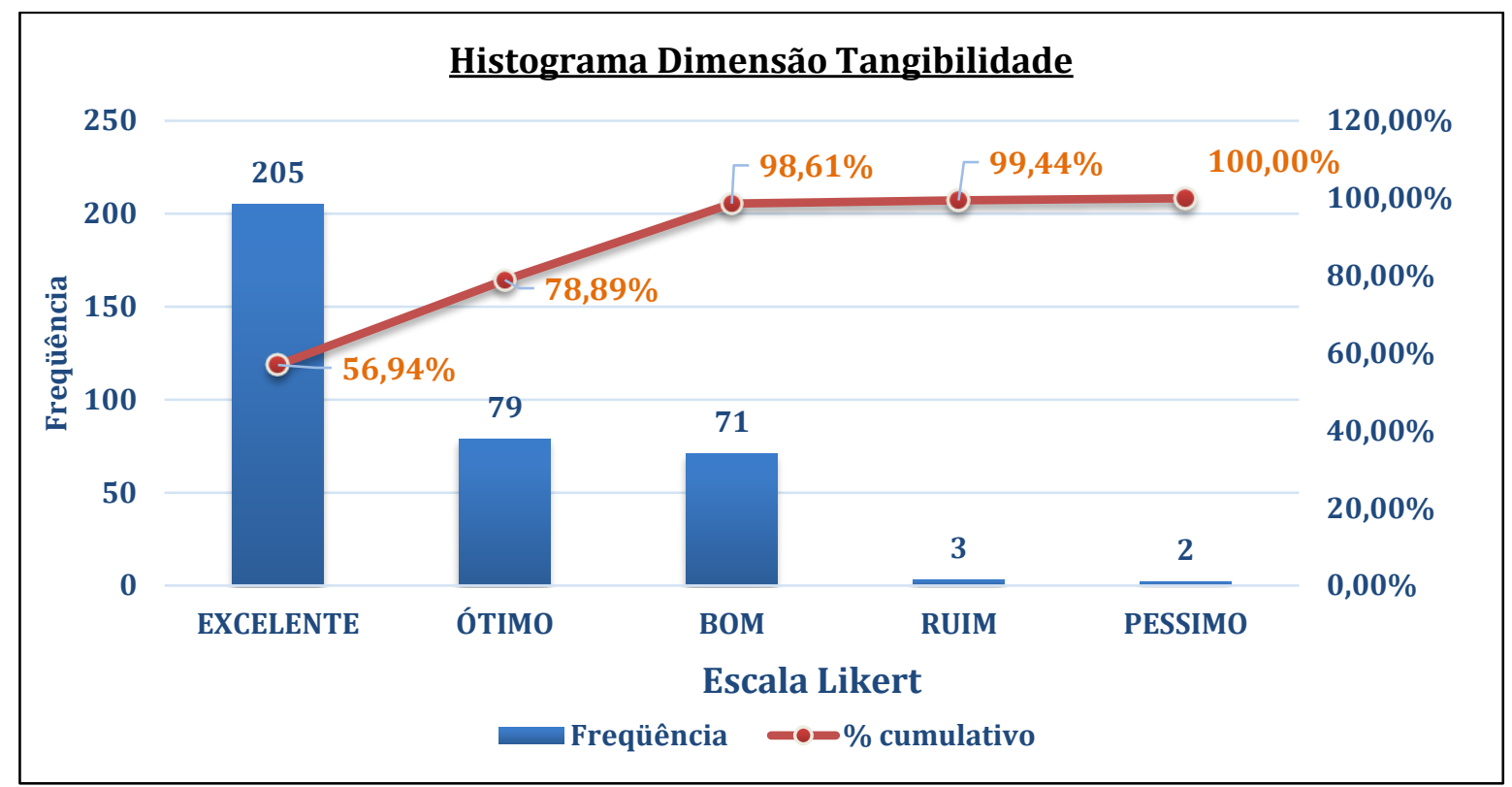

Fonte: Autores, 2021

Assim sendo, pode-se verificar que na dimensão "Tangibilidade" a percepção atingiu a expectativa, mostrando que os aspectos tangíveis da empresa são satisfatórios. Excelente 56,94\%, ótimo 21,95\%, Bom 19,72\%, ruim 0,83\% e péssimo 0,56\%. A Tabela 3 apresenta os dados na dimensão "Confiabilidade" que se refere a habilidade de realizar o serviço prometido de forma confiável e acurada.

Tabela 3 - Resultados da dimensão "Confiabilidade".

\begin{tabular}{|c|c|c|c|c|c|}
\hline DIMENSÃO & QUESTÃO & PERCEPÇÃO & EXPECTATIVA & P-E & PORCENTAGEM INDIVIDUAL \\
\hline & 6 & 4,75 & 4 & 0,75 & $95 \%$ \\
\hline$a_{0}$ & 7 & 4,76 & 4 & 0,76 & $95 \%$ \\
\hline & 8 & 4,61 & 4 & 0,61 & $92 \%$ \\
\hline 38 & 9 & 4,61 & 4 & 0,61 & $92 \%$ \\
\hline $\mathrm{C}^{5}$ & 10 & 4,75 & 4 & 0,75 & $95 \%$ \\
\hline & MÉDIA & 4,70 & 4 & \multicolumn{2}{|c|}{$94 \%<=$ TAXA DE SATISFAÇÃO } \\
\hline
\end{tabular}

Fonte: Autores, 2021

Observa-se na Tabela 3, os dados da pesquisa revelam que todos os itens da dimensão "Confiabilidade" estão acima da expectativa padronizada pela confeitaria Ganache Bolos. No item 6 (Atendimento) obteve-se 95\% de satisfação do cliente, um índice de 4,75 , ou seja $(0,75)$ acima da média mínima estipulada. No item 7 
(Atendimento via aplicativo) obteve-se um índice de 4,76, $(0,76)$ acima da média estipulada com 95\% de satisfação dos clientes. No item 8 (Valor do produto) obteve-se um índice de 4,61, $(0,61)$ acima da média estipulada, assim tendo $92 \%$ de satisfação dos clientes. No item 9 (CustolBenefício) obteve-se um índice de 4,61, $(0,61)$ acima da média estipulada tendo-se 92\% de satisfação do cliente. No item 10 (Qualidade do produto) obteve-se um índice de 4,75, $(0,75)$ acima da média estipulada, tendo-se $95 \%$ de satisfação dos clientes.

Ao final dos dados analisados pela planilha SERVQUAL, obteve-se uma satisfação geral da dimensão "Confiabilidade" de 94\% dos clientes. Assim sendo, podese verificar que na dimensão "Confiabilidade" a percepção atingiu a expectativa mínima padronizada pela confeitaria Ganache Bolos, mostrando que os aspectos de confiabilidade da empresa são satisfatórios. Abaixo o histograma da dimensão confiabilidade (Gráfico 2) ilustrando os dados no diagrama de Pareto.

Gráfico 2 - Histograma dimensão "Confiabilidade"

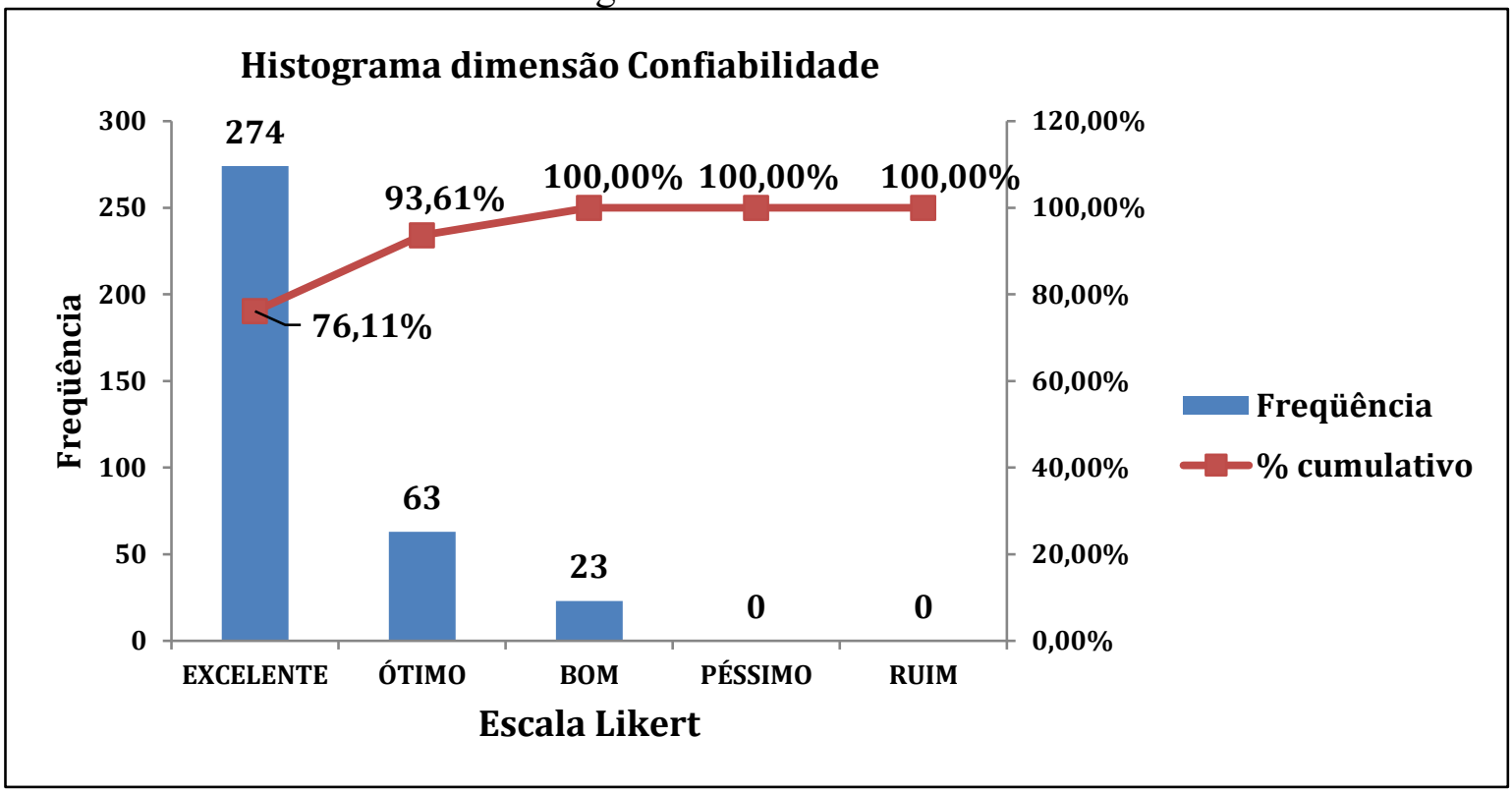

Fonte: Autor, 2021

A Tabela 4 abaixo apresenta os dados obtidos sobre a dimensão "Presteza", que se refere à disposição de atender os clientes e de prestar serviço de forma ágil e rápida. Excelente $76,11 \%$, ótimo $23,89 \%$, bom $6,39 \%$, péssimo $0 \%$ e ruim $0 \%$. 
Tabela 4 - Resultados da dimensão da "Presteza"

\begin{tabular}{|c|c|c|c|c|c|}
\hline DIMENSÃO & QUESTÃO & PERCEPÇÃO & EXPECTATIVA & P-E & PORCENTAGEM INDIVIDUAL \\
\hline & 11 & 4,69 & 4 & 0,69 & $94 \%$ \\
\hline & 12 & 4,67 & 4 & 0,67 & $93 \%$ \\
\hline & 13 & 4,6 & 4 & 0,60 & $92 \%$ \\
\hline & 14 & 4,69 & 4 & 0,69 & $94 \%$ \\
\hline & 15 & 4,74 & 4 & 0,74 & $95 \%$ \\
\hline & MÉDIA & 4,68 & 4 & $94 \%$ & $<=$ TAXA DE SATISFAÇÃO \\
\hline
\end{tabular}

Fonte: Autores, 2021

Observa-se os dados obtidos na Tabela 4 que todas as questões da dimensão "Presteza" obtiveram notas acima da padronizada pela confeitaria Ganache Bolos como mínima. No item 11 (Agilidade do atendimento) obteve-se um índice de 4,69, $(0,69)$ acima da média estipulada, tendo-se uma aprovação de 94\% dos clientes. No item 12 (Entrega) obteve-se um índice de 4,67, $(0,67)$ acima da média estipulada como mínima. Tendo-se uma aprovação de 93\% dos clientes. No item 13 (Forma de entrega) obteve-se um índice de 4,60, $(0,60)$ acima da média estipulada como mínima.

Tendo uma aprovação de $92 \%$ dos clientes. No item 14 (Agilidade \simpatia do entregador) obteve-se um índice de 4,69, $(0,69)$ acima da média mínima estipulada. Tendo uma aprovação de 94\% dos clientes. No item 14 (Agilidade no pagamento) obteve-se um índice de 4,74, $(0,74)$ acima da medida mínima estipulada. Tendo a aprovação de 95\% dos clientes. Abaixo o histograma da dimensão Presteza (Gráfico 3) ilustrando os dados no diagrama de Pareto.

Gráfico 3 - Histograma dimensão "Presteza"

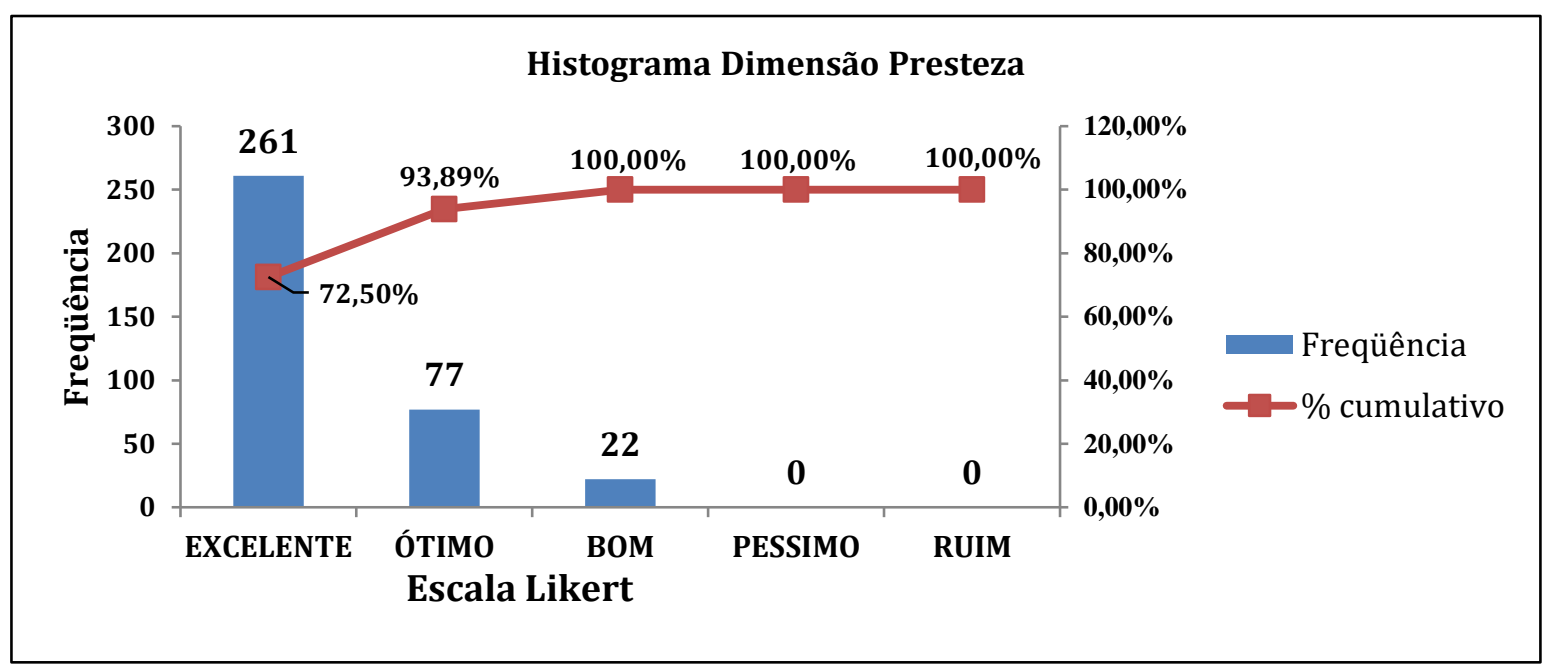

Fonte: Autores, 2021 
Ao final dos dados analisados pela planilha SERVQUAL, obteve-se uma satisfação geral da dimensão "Presteza" de 94\% dos clientes. Assim sendo, pode-se verificar que na dimensão "Presteza" a percepção atingiu a expectativa mínima padronizada pela confeitaria Ganache Bolos, mostrando que os aspectos analisados da empresa são satisfatórios. Excelente 72,50\%, ótimo 21,39\%, Bom 6,11\%, péssimo 0\% e ruim $0 \%$.

A Tabela 5 abaixo apresenta os dados obtidos sobre a dimensão "segurança" que se refere ao conhecimento e cortesia dos empregados e habilidade de transmitir confiança e segurança.

Tabela 5 - Resultados da dimensão da "Segurança"

\begin{tabular}{|c|c|c|c|c|c|}
\hline DIMENSÃO & QUESTÃO & PERCEPÇÃO & EXPECTATIVA & P-E & PORCENTAGEM INDIVIDUAL \\
\hline & 16 & 4,71 & 4 & 0,71 & $94 \%$ \\
\hline$s^{c t}$ & 17 & 4,68 & 4 & 0,68 & $94 \%$ \\
\hline$p^{p r}$ & 18 & 4,64 & 4 & 0,64 & $93 \%$ \\
\hline & 19 & 4,50 & 4 & 0,50 & $90 \%$ \\
\hline & MÉDIA & 4,63 & 4 & \multicolumn{2}{|c|}{ 93\% TAXA DE SATISFAÇÃO } \\
\hline
\end{tabular}

Fonte: Autores, 2021

Constata-se que no item da dimensão "Segurança" que se refere ao conhecimento dos colaboradores, a percepção ultrapassou a média mínima estabelecida, mostrando dessa forma que de acordo com os clientes, os colaboradores têm conhecimentos suficientes para responder os questionamentos dos clientes.

No item 16 (Confiança nos produtos), obteve-se um índice de 4,71, $(0,71)$ acima da média estipulada como mínima. Tendo 94\% de aprovação dos clientes. No item 17 (Confiança nos serviços), obteve-se um índice de 4,68, $(0,68)$ acima da média mínima estipulada. Tendo 94\% de aprovação dos clientes. No item 18 (Embalagem) obteve-se um índice de 4,64, $(0,64)$ acima da média mínima estipulada.

Tendo como resultado 93\% de aprovação dos clientes. No item 19 (Medidas de segurança covid-19) obteve-se um índice de 4,50, $(0,50)$ acima da média mínima estipulada. Tendo um resultado de $90 \%$ de satisfação dos clientes. Abaixo o histograma da dimensão Segurança (Gráfico 4) ilustrando os dados no diagrama de Pareto. 
Gráfico 4 - Histograma dimensão "Segurança”"

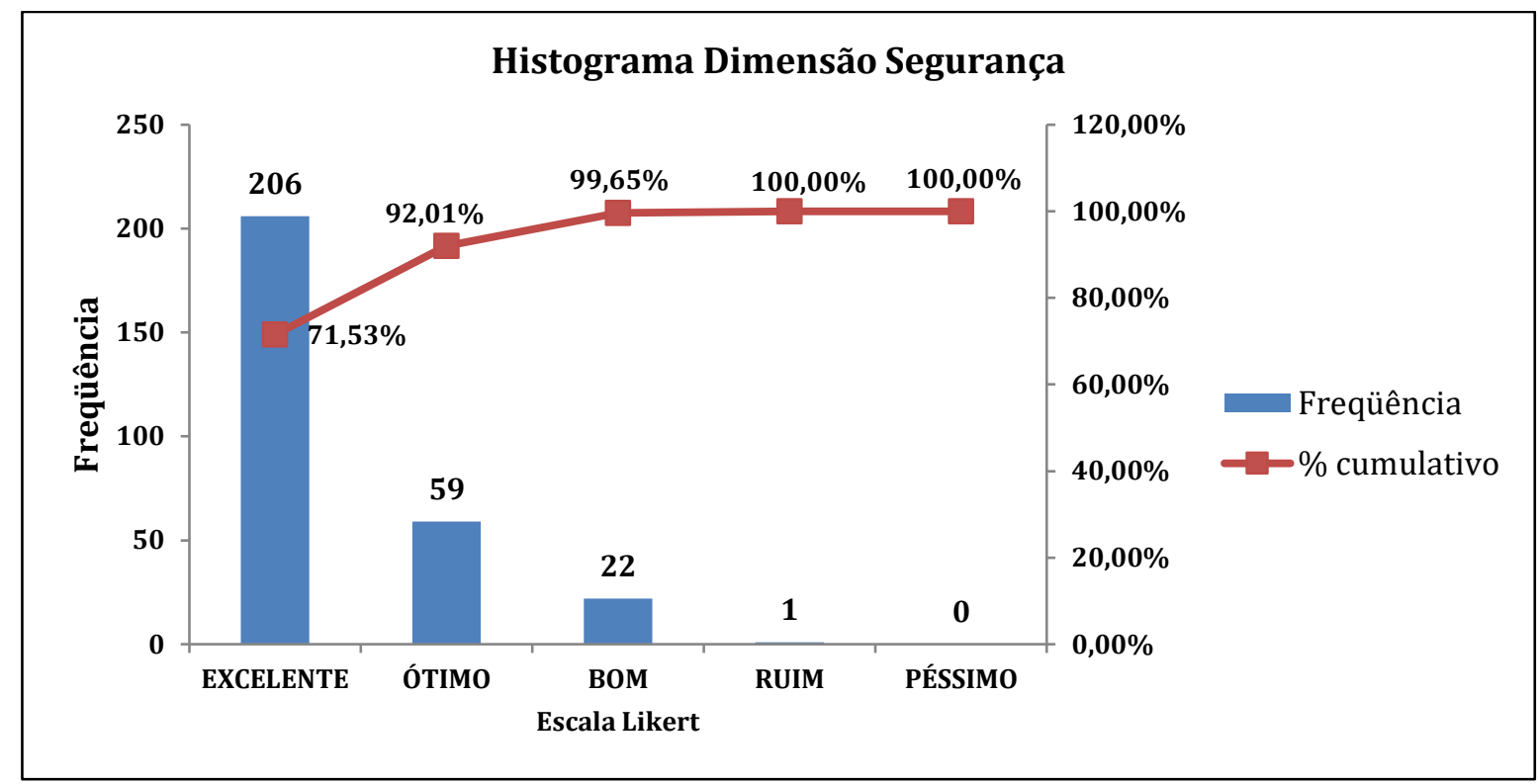

Fonte: Autores, 2021

Ao final dos dados analisados pela planilha SERVQUAL, obteve-se uma satisfação geral da dimensão "Segurança" de 93\% dos clientes. Assim sendo, pode-se verificar que na dimensão "Segurança" a percepção atingiu a expectativa mínima padronizada pela confeitaria Ganache Bolos, mostrando que os aspectos analisados da empresa são satisfatórios. Excelente 71,53\%, ótimo 20,48\%, Bom 7,64\%, ruim 0,35\% e péssimo 0\%. A Tabela 6 abaixo apresenta os dados obtidos sobre a dimensão "Empatia" que se refere ao tratamento do cliente com cordialidade, cuidado e atenção individual.

Tabela 6 - Resultados da dimensão da "Empatia"

\begin{tabular}{|c|c|c|c|c|c|}
\hline DIMENSÃO & QUESTÃO & PERCEPÇÃO & EXPECTATIVA & P-E & PORCENTAGEM INDIVIDUAL \\
\hline & 20 & 4,58 & 4 & 0,58 & $92 \%$ \\
\hline & 21 & 4,65 & 4 & 0,65 & $93 \%$ \\
\hline$s b^{p}$ & 22 & 4,53 & 4 & 0,53 & $91 \%$ \\
\hline s & 23 & 4,68 & 4 & 0,68 & $94 \%$ \\
\hline & MÉDIA & 4,64 & 4 & \multicolumn{2}{|c|}{$93 \%<=$ TAXA DE SATISFAÇÃO } \\
\hline
\end{tabular}

Fonte: Autores, 2021

De acordo com a Tabela 6, a pesquisa SERVQUAL obteve os seguintes resultados. No item 20 (Variedades de sabores) obteve-se um índice de 4,58, $(0,58)$ 
acima da média estipulada como mínimo. Tendo aprovação de $92 \%$ dos clientes. No item 21 (Tamanholquantidade) obteve-se um índice de 4,65, (0,65) acima da média mínima estipulada. Tendo 93\% de aprovação dos clientes. No item 22 (compreensão da necessidade do cliente) obteve-se um índice de 4,53, $(0,53)$ acima da média mínima estipulada. Tendo $91 \%$ de aprovação dos clientes. No item 23 (Atendimento geral) obteve-se um índice de 4,69, $(0,68)$ acima da média mínima estipulada. Tendo 94\% de aprovação dos clientes entrevistados. No Gráfico 5 o histograma ilustrando os dados no diagrama de Pareto.

Gráfico 5 - Histograma dimensão "Empatia"

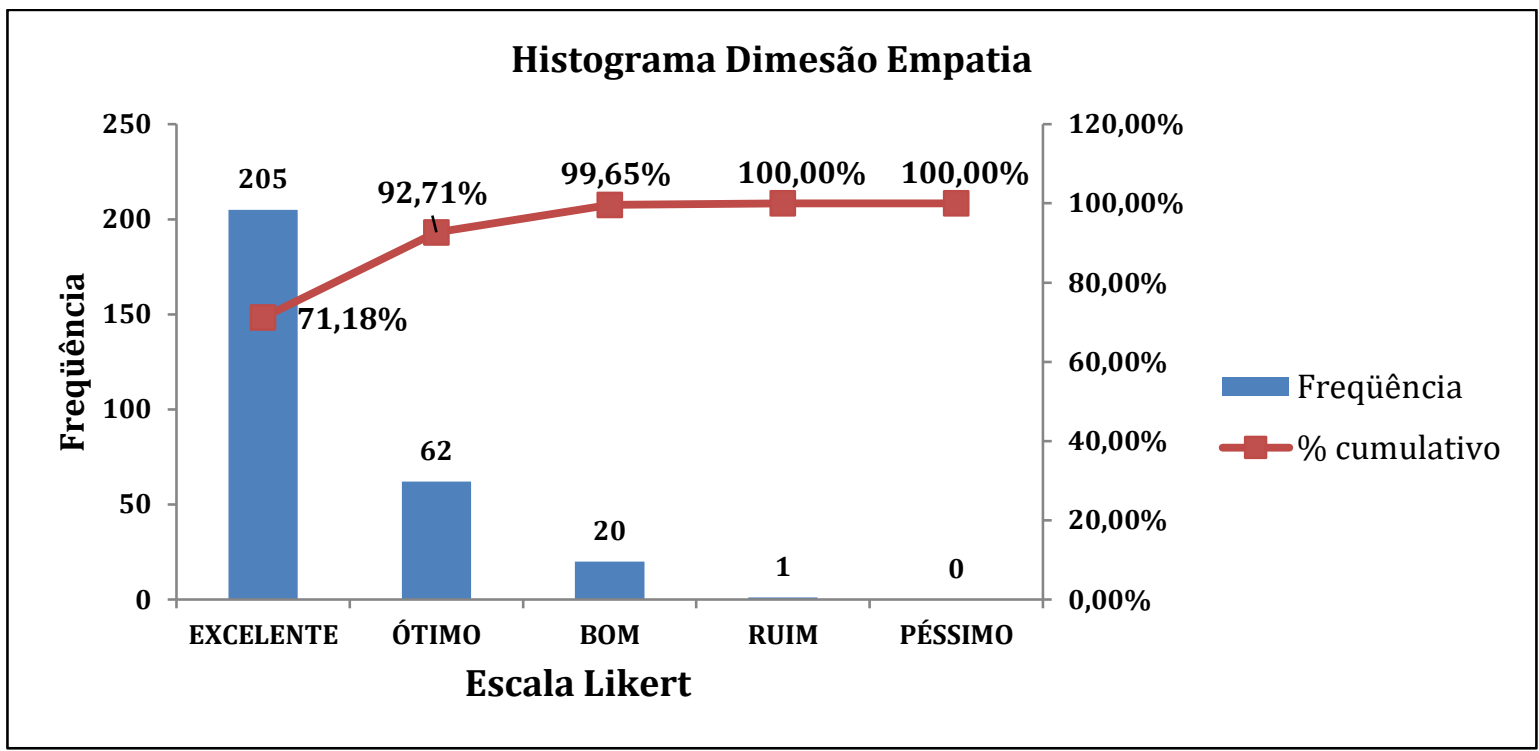

Fonte: Autores, 2021

Ao final dos dados analisados pela planilha SERVQUAL, obteve-se uma satisfação geral da dimensão "Empatia" de 93\% dos clientes. Assim sendo, pode-se verificar que na dimensão "Empatia" a percepção atingiu a expectativa mínima padronizada pela confeitaria Ganache Bolos, mostrando que os aspectos analisados da empresa são satisfatórios. Excelente 71,18\%, ótimo 21,53\%, bom 6,94\%, ruim 0,35\% e péssimo $0 \%$. Abaixo o Gráfico 6 da taxa de satisfação consolidada dos clientes pesquisados. 
Gráfico 6 - Taxa de satisfação consolidados.

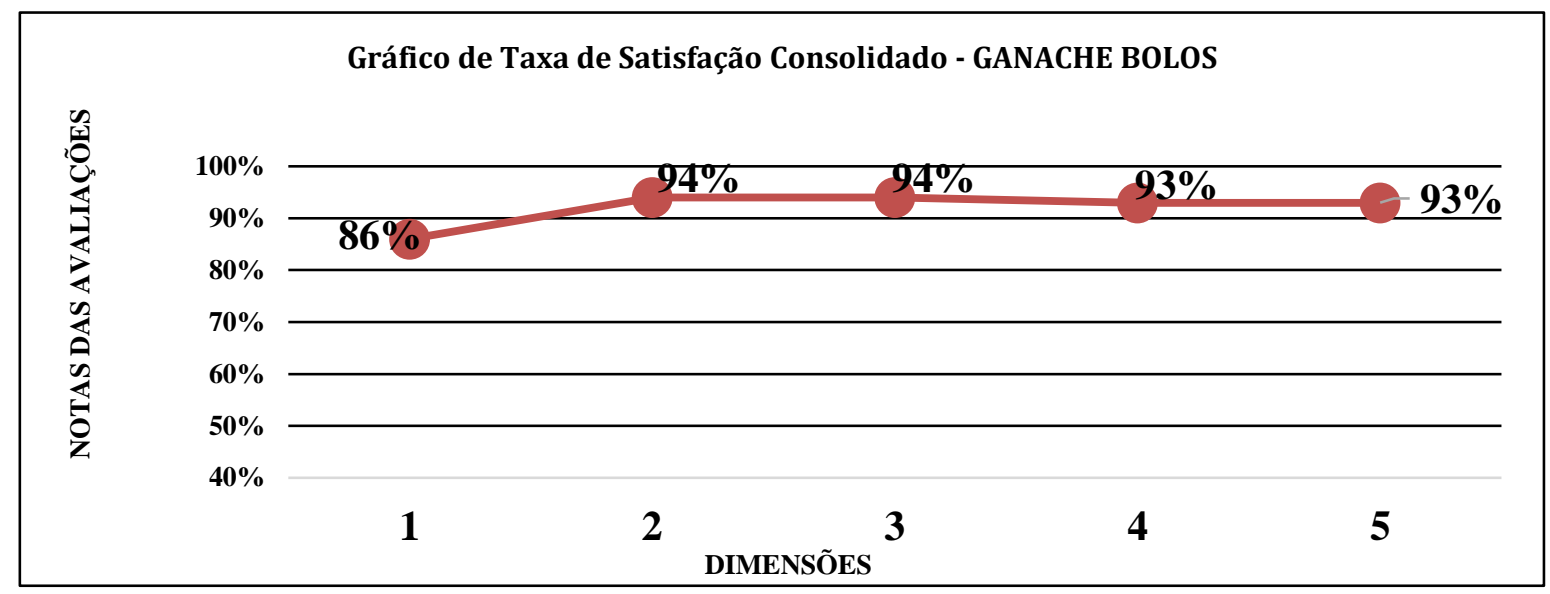

Fonte: Autores, 2021.

Apesar de todas as dimensões estarem acima da média padronizada pela confeitaria, conforme mostrado no gráfico acima, nota-se que as dimensões "confiabilidade" e "presteza" se destacaram com a maior porcentagem de satisfação dos clientes, seguidas das dimensões "Segurança" e "empatia" com 93\% de satisfação dos clientes e a dimensão "tangibilidade" com $86 \%$ de aprovação dos clientes pesquisados.

\section{CONCLUSÃO}

É importante que as empresas realizem pesquisas com seus clientes para saber se estão fornecendo serviços de qualidade. O modelo SERVQUAL é bastante eficaz quando se deseja realizar uma pesquisa de qualidade do serviço. Fundamentado nos resultados da pesquisa as áreas consideradas fracas podem ser localizadas e corrigidas com planos de ação e ferramentas de gestão de gerenciamento, possibilitando também apontar as áreas fortes da empresa, que podem ser usadas como vantagens competitivas.

O objetivo geral deste trabalho é realizar uma pesquisa de campo para mensurar a percepção do cliente em relação à qualidade dos serviços prestados na confeitaria Ganache Bolos e assim estudar os resultados obtidos pelo método Servqual como um instrumento de competitividade e melhoria dos serviços e produtos. O modelo foi adaptado para a sua aplicação com os clientes da Ganache Bolos. Dessa forma, pode-se avaliar a percepção que os clientes têm em relação aos serviços prestados e produtos. 
Tomando como base o estudo de caso realizado observou-se que todas as dimensões pesquisadas se mantiveram acima da expectativa dos clientes, sinalizando que a confeitaria até o presente momento não necessita de uma intervenção gerencial de urgência, porém a mesma pesquisa pode ser usada para aprimorar seus serviços e produtos.

Apesar da grande contribuição que uma análise como o SERVQUAL pode proporcionar ao prestador de serviço, é importante destacar que o desenvolvimento da pesquisa apresentou algumas limitações, como por exemplo, os resultados apresentados mostram apenas a avaliação da qualidade dos serviços prestados pela confeitaria Ganache Bolos em um período específico (um mês), e de acordo com o ponto de vista de uma amostra de clientes.

Dessa forma, para uma análise mais conclusiva seria importante como sugestão para trabalhos futuros que as avaliações fossem feitas de forma periódica, a cada 2 meses. Sugere-se, também, que seja dado continuidade na pesquisa desenvolvida, no sentido de avaliar os impactos causados por investimentos nas principais oportunidades de melhoria destacadas por meio da aplicação da ferramenta SERVQUAL, podendo a empresa instalar questionários fixos, com o objetivo de captar sugestões dos clientes que se mostram insatisfeitos com determinados aspectos da empresa.

\section{REFERÊNCIAS}

MAURICIO OLBRICK RODRIGUES, Avaliação da qualidade do transporte coletivo da cidade de São Carlos, São Carlos, 2006.

ANDREY SARTORI, RUBENS OLIVEIRA, MÁRCIA H. SCABORA, FABRÍCIO MORAES, MOISÉS P. BOTELHO, Avaliação da qualidade dos serviços prestados por uma Instituição de Ensino Superior utilizando a escala SERVQUAL, Cuiabá, 2016. Disponível em

https://www.researchgate.net/publication/320840294_Avaliacao_da_qualidade_dos_ser vicos_prestados_por_uma_Instituicao_de_Ensino_Superior_utilizando_a_escala_SERV QUAL

ANDREY SARTORI, MOISÉS P. BOTELHO, FABRÍCIO MORAES, BRUNA V. SOUZA, MIRIAN V.M.A. DE MACEDO. Avaliação da qualidade dos serviços de transporte público urbano em Cuiabá e Várzea Grande utilizando o método SERVQUAL, Cuiabá, 2018. Disponível em https://www.academia.edu/37570447/AVALIA\%C3\%87\%C3\%830_DA_QUALIDAD E_DOS_SERVI\%C3\%87OS_DE_TRANSPORTE_P\%C3\%9ABLICO_URBANO_EM 
_CUIAB\%C3\%81_E_V\%C3\%81RZEA_GRANDE_UTILIZANDO_M\%C3\%89TOD O_SERVQUAL_EVALUATION_OF_THE_QUALITY_OF_URBAN_PUBLIC_TRA NSPORT_SERVICES_IN_CUIAB\%C3\%81_AND_V\%C3\%81RZEA_GRANDE_USI NG_SERVQUAL_METHOD

ANDREY SARTORI, FABRÍCIO MORAES, ANDERSON N. C. VIEIRA, ROSICLEY N. DE SIQUEIRA, ANDRESSA KARYNNE RODRIGUES DA SILVA. Avaliação dos serviços de transporte urbano prestados por um aplicativo nas cidades de Cuiabá e Várzea Grande - MT através do método SERVQUAL, Cuiabá, 2019. Disponível em:

<https://www.researchgate.net/publication/335892587_AVALIACAO_DOS_SERVIC OS_DE_TRANSPORTE_URBANO_PRESTADOS_POR_UM_APLICATIVO_NAS_ CIDADES_DE_CUIABA_E_VARZEA_GRANDE__MT_ATRAVES_DO_METODO_SERVQUAL>

ASSOCIAÇÃO BRASILEIRA DE NORMAS TÉCNICAS. ABNTNBR ISO 9001:2008: requisitos para um sistema de gestão da qualidade. Rio de Janeiro, 2008. Disponível em:

http://www.standardconsultoria.com/f/files/ced37e4b0cf7f91b80e9ca61ceefe586203661 1357.pdf

BATESON, J. E. G.; HOFFMAN, K. D. Marketing de serviços. 4. ed. Porto Alegre: Bookman, 2001.

FITZSIMMONS, James A.; FITZSIMMONS, Mona J.. Administração de Serviços: Operações, estratégia e tecnologia da informação. Porto Alegre: Amgh, 2014;

FITZSIMMONS, J. A. I.; FITZSIMMONS. M. J. Administração de serviços: operações, estratégias e tecnologia de informação. 2. ed. Porto Alegre: Bookman, 2000.

GOLDENBERG, M. A arte de pesquisar: como fazer pesquisa qualitativa em ciências sociais. 3.ed. Rio de Janeiro: Record, 1999.

HARGREAVES, L.; ZUANETTI, R.; LEE, R. Qualidade em prestação de serviços. 2 ed. Rio de Janeiro: Editora Senac Nacional, 2001.

HOFFMAN, K.D.; BATESTON, J.E.G. Princípios do Marketing de Serviços: conceito, estratégias e casos. 2 eds. Cengage Learnign, 2008.

KOTLER, P.; HAYES, T.; BLOOM P. N. Marketing de serviços profissionais: estratégias inovadoras para impulsionar sua atividade, sua imagem e seus lucros. 2. ed. Barueri: Manole, 2002.

KOTLER, P.; KELLER, K.L. Administração de Marketing. 12. ed. Person Prentice Hall, 2006.

LACERDA, F. A. B. Gestão da qualidade: fundamentos da excelência. Brasília: SEBRAE, 2005. 
LAS CASAS, A. 1. Marketing de Serviços. 5. ed. São Paulo, 2010.

MATTAR, F. N. Pesquisa de Marketing. 5. ed. São Paulo: Atlas, 1999

MALHOTRA, N. Pesquisa de marketing: uma orientação aplicada. $4^{\text {a }}$ edição. Porto alegre: Bookman, 2006;

PALADINI, P. Gestão da qualidade: teoria e prática. 3. ed. São Paulo: Atlas, 2012.

PARASURAMAN, A.; ZEITHAML, V. A.; BERRY, L. L. A conceptual model of services quality and its implication for future research. Journal of Marketing 2014.

SOUZA, Enrico Ramos Aleixo de. ANÁLISE DA SATISFAÇÃO DE CLIENTES DE SERVIÇOS DE SUPORTE A UM SISTEMA DE GERENCIAMENTO DA CADEIA DE SUPRIMENTOS. 2009. 135 f. TCC (Graduação) - Curso de Engenharia de Produção, Escola Politécnica da Universidade de São Paulo, São Paulo, 2009.

TOLEDO, J. C. Gestão da qualidade na agroindústria. In: BATALHA, M. O. (Org.). Gestão agroindustrial. 2. ed. São Paulo: Atlas, 2001.

ZEITHAML, V. A.; BITNER, M. J. Marketing de serviços: a empresa com foco no cliente. 2. ed. Porto Alegre: Bookman, 2003.

ZEITHAML, V. A.; PARASURAMAN, A.; BERRY L. L. Delivering Quality Service: Balancing Costumer Perception and Expectation. New York: The Free Press, 1990. 